\title{
Hibiscus ameliorates salt-induced carotid intima-media thickness in albino rats
}

\author{
Fidel O. Gwala (D), William O. Sibuor (D), Beda O. Olabu (D), Anne N. Pulei (D), Julius A. Ogeng'o (D) \\ Department of Human Anatomy, School of Medicine, University of Nairobi, Nairobi, Kenya
}

\begin{abstract}
Objectives: The carotid intima-media thickness (CIMT) is a known biomarker of clinical and subclinical cardiovascular events and evaluation of therapeutic action. Excessive salt directly causes changes in the common carotid intima and media layers and has been linked to hypertensive disease resulting to changes on vascular structure. Hibiscus sabdariffa is a traditional herbal drink with antihypertensive effects. The anatomical aspects of its effects however, are largely unknown. This study therefore, investigated the effects of hibiscus extract on CIMT in rats fed with a high-salt diet.

Methods: Young albino rats (Rattus norvegicus) were divided into three groups: (A) high-salt diet alone, (B) high-salt diet and Hibiscus sabdariffa extract and (C) control group fed a normal diet for 8 weeks. Specimens from carotid arteries of rats were fixated and processed for paraffin embedding. Seven-micrometer thick sections were stained with Hematoxylin and Eosin stain and examined under light microscopy. Morphometric measurements were taken to determine the CIMT.

Results: High-salt diet increased CIMT from $497.86 \mu \mathrm{m}$ to $697.85 \mu \mathrm{m}$ in 8 weeks. In Hibiscus sabdariffa extract fed rats, the CIMT decreased to $542.85 \mu \mathrm{m}(\mathrm{p}<0.05)$ by week 8 .

Conclusion: Hibiscus sabdariffa extract ameliorates salt-induced increase in CIMT in rats in a time-dependent manner. This implies that Hibiscus sabdariffa products may have therapeutic value in salt-induced vascular morbidity.
\end{abstract}

Keywords: carotid intima-media thickness; hibiscus; salt diet

Anatomy 2019;13(2):92-97 @2019 Turkish Society of Anatomy and Clinical Anatomy (TSACA)

\section{Introduction}

Excessive salt intake has been reported to increase blood pressure and plays a role in damaging cardiovascular structure and causing dysfunctions such as endothelial dysfunction and kidney disease progression. ${ }^{[1,2]}$ It is also associated with greater risk of cardiovascular and cerebrovascular diseases including atherosclerosis and stroke. ${ }^{[3,4]}$ These pathological processes increase risk of cardiovascular morbidity and mortality. ${ }^{[5,6]}$ Direct anatomical implications of high sodium consumption in particular result in vascular hypertrophy and collagen deposition and increased carotid intima-media thickness (CIMT). ${ }^{[7]}$ CIMT is a good surrogate marker of subclinical atherosclerosis and progressive cardiovascular disease. ${ }^{[8]}$ There is considerable high-salt intake and burden of cardiovascular disease morbidity and mortality worldwide, especially in middle and low-income countries. ${ }^{[5,9]}$ Despite this, adherence to conventional treatment regi- mens such as elective dietary salt restriction has faced difficulties. With more than $50 \%$ non-compliance rates, the emergence of alternative therapies creates more attractive treatment options. ${ }^{[10]}$

Hibiscus sabdariffa extract reduces blood pressure in a dose dependent manner ${ }^{[11,12]}$ and has possible therapeutic effects on oxidative stress, lipid profile and atherosclerosis. ${ }^{[13]}$ It is used primarily as a traditional remedy for hypertension. ${ }^{[10]}$ Furthermore, because of the reported safety for long term administration of Hibiscus sabdariffa extract (HSE) as an antihypertensive, ${ }^{[14,15]}$ it provides an effectively manageable diet-imposed therapy that is low on cost and easily available. Among the salt-induced structural changes, CIMT is a particularly potent indicator of vascular disease with predictive staging, diagnostic and follow up prognostic value. ${ }^{[1,17]}$ It could as well be used to evaluate the therapeutic effectiveness of HSE in partly reducing cardiovascular disease risk. ${ }^{[18]}$ 
Data on structural effects of Hibiscus sabdariffa on blood vessels is critical in elaborating the mechanisms. However, the effect of HSE on salt-induced changes in CIMT has not been reported before. This study therefore examined the effects of HSE on salt-induced changes in CIMT.

\section{Materials and Methods}

This study was performed on 24 two-month old albino rats (Rattus norvegicus) obtained from the Department of Biochemistry of University of Nairobi. Ethical approval for the study was obtained from the Bio-Safety, Animal Use and Ethics Committee, Faculty of Veterinary Medicine, University of Nairobi, approval number: FVB/BAUE/ 2017/130. The rats were randomly selected by simple random sampling and marked 1-24. The numbers were then fed into a random number generating software. From this, 8 random numbers were obtained for each of the 3 groups $(\mathrm{A}-\mathrm{C})$. The rats were randomly assigned into baseline $(n=2)$, experimental $(n=16)$ and control $(\mathrm{n}=8)$ groups. At experiment weeks 2, 5 and 8, six rats from the two experimental group and two rats from the control group were euthanized. Group A was fed a diet containing 8\% sodium chloride, Group B 8\% sodium chloride and HSE by gavage and Group C (control group) was fed on standard pellets. Feeding was evaluated by a feed efficiency ratio to determine how much food each rat consumed. Water was provided ad libitum.

Dry dark-red calyces of Hibiscus sabdariffa were purchased from the local market. The technicians at the Herbarium of the Department of Botany, University of Nairobi, facilitated identification of the plant material. Thirty grams of the calyces were brewed in $200 \mathrm{ml}$ of boiled water and allowed to stand for 30 minutes. The resulting mixture of calyces and brewed extract was then filtered and the solution evaporated to dryness giving a dark red powder (yield: $55 \%$ ). The dry extract was stored at $4{ }^{\circ} \mathrm{C}$ to keep it from growing mould ${ }^{[12]}$ and dissolved in distilled water at room temperature and administered orally by gavage.

Standard iodized salt (sodium chloride) was purchased from the local supermarket. Seventy-seven grams of sodium chloride $(\mathrm{NaCl})$ were added to $923 \mathrm{~g}$ of standard rat chow. One kilogram of standard rat chow contained $0.3 \%$ $\mathrm{NaCl}$. The standard rat chow and $\mathrm{NaCl}$ were then mixed thoroughly to get an $8 \% \mathrm{NaCl}$ diet. ${ }^{[19]}$

On tissue harvesting, the animals were anaesthetized by halothane and perfused with $10 \%$ formalin solution. After perfusion, the common carotid arteries (CCAs) were harvested by extending the midline body incision up to the neck region and reflecting the skin flaps laterally. The right CCA was identified at its junction with the brachiocephalic trunk and the right subclavian artery and the left were identified branching from the arch of the aorta. The whole length of the artery was harvested on both sides up to just before the bifurcation into internal and external carotid arteries.

Whole CCAs were fixed in 10\% formal saline for at least 24 hours. $1 \mathrm{~mm}$ long samples obtained from the middle of the specimen were dehydrated in increasing grades of alcohol, cleared in toluene and embedded in paraffin wax. Seven-micrometer thick sections were deparaffinized in xylene, rehydrated and stained with Hematoxylin and Eosin. The slides were examined with a light microscope.

Photomicrographs of the sections were taken using a Canon digital camera (12 megapixels) mounted on a photomicroscope. These photographs were processed using the Fiji-ImageJ (NIH, Bethesda, MD, USA) software for morphometric and stereological analysis. The c-IMT was determined through four random points. Five different 7 $\mu \mathrm{m}$ sections were sampled from each animal by simple random sampling. Photomicrographs were taken from each section and examined at a magnification of $\times 400$. Four random points were traced on the wall of the CCA over the intimal-media zone in the photomicrograph of each section (Figure 1). The average measure of CIMT was then calculated from the four points as shown follows:

$$
I M T=(I M T a+I M T b+I M T c+I M T d) / 4
$$

\section{Results}

The CCA displayed three distinct histological layers characteristic of a typical elastic artery: an innermost tunica intima, tunica media and an outermost tunica adventitia The CIMT was $282.26 \mu \mathrm{m}$ at week 0 . It increased in all the groups across the total duration of the study (Figure 2). The increase was a statistically significant from week 2 to week 8 (Figure 3a) in the control group, being 368.23 $\mu \mathrm{m}$ at week 2 and $512.98 \mu \mathrm{m}$ at week 8 . A similar statistically significant increase was observed in the experimental groups. In the high-salt group, the mean CIMT increased from $497.86 \mu \mathrm{m}$ in week 2 to $697.85 \mu \mathrm{m}$ in week 8 (Figure $3 \mathbf{b}$ ), whereas in the high-salt with HSE group it increased to $542.85 \mu \mathrm{m}$ by the 8 th week (Figure 3c). The CIMT was most marked by the 8 th week. Concurrent administration of HSE with high-salt loading led to a less pronounced increase in CIMT compared to the high-salt group alone during the entire study period (Figure 3c). At the 8th week, the difference among the three groups was statistically significant (Figure 2). 


\section{Discussion}

High dietary salt intake induced notable increase in CIMT, similar to that reported in earlier studies. ${ }^{[20,21]}$ Safar et al. ${ }^{[2]}$ demonstrated an increase in CIMT alongside the arterial wall in rats fed a high-salt diet. It was also suggested that high urinary sodium levels resulted from high-salt diets such as from processed foods. Similarly, a positive correlation between urinary sodium levels and CIMT was established..$^{[7,21,22]}$

The potential blood pressure independent cardiovascular disease risk under a high-salt diet may be related to cardiovascular functional and structural changes. This could be through alterations in shear stress and endothelial function. ${ }^{[2,24]}$ Such alterations can cause vascular hypertrophy and collagen accumulation ${ }^{[23]}$ which increase CIMT. Vascular smooth muscle cells undergo modulation of growth, proliferation, hypertrophy and even apoptosis through effects of various isoforms of TGF$\beta .^{[25]}$ In addition, TGF- $\beta$ down regulates proteolytic extracellular matrix (ECM) molecules such as matrix metalloproteinases (MMPs). In particular, MMP-2 and 9 are thought to be specifically involved in collagen breakdown in the $\mathrm{CCA}^{[22]}$ and their hindrance by TGF- $\beta$ could contribute immensely to increased collagen deposition in the tunica media. These findings are consistent with the association of high sodium intake with greater presence of carotid atherosclerosis. ${ }^{[21]}$

On the contrary, when HSE was concurrently administered with a high-salt diet, it decreased the amount of intima-media thickening. Attenuation of high-salt-induced thickening in the intima and media of the aorta was similarly demonstrated using garlic extract. ${ }^{[26]}$ Like garlic, a variety of plant extracts show potential to reduce intima-media thickening ${ }^{[27]}$ particularly via inhibition of angiotensin converting enzyme (ACE). Hibiscus sabdariffa, similarly, has been reported to demonstrate ACE inhibiting properties. ${ }^{[10]}$ This reduces release of angiotensin II which plays a major role in vascular smooth muscle cells hypertrophy. Previous histopathological experiments reveal that HSE reduces foam cell formation and inhibits vascular smooth muscle cell migration and calcification in blood vessels of rabbits. ${ }^{[28]}$ Hibiscus significantly reduced severe atherosclerosis in the aorta of the rabbits and thus, showing antiatherosclerotic activity.

In vitro, in vivo and clinical studies have provided evidence of hypolipidemic and anti-hypertensive effects of HSE which are linked to its antioxidant activities, inhibition of ACE, vaso-relaxant, antiatherogenic, anti-inflammatory and endothelial stabilizing properties. ${ }^{[11,29-31]}$ Its

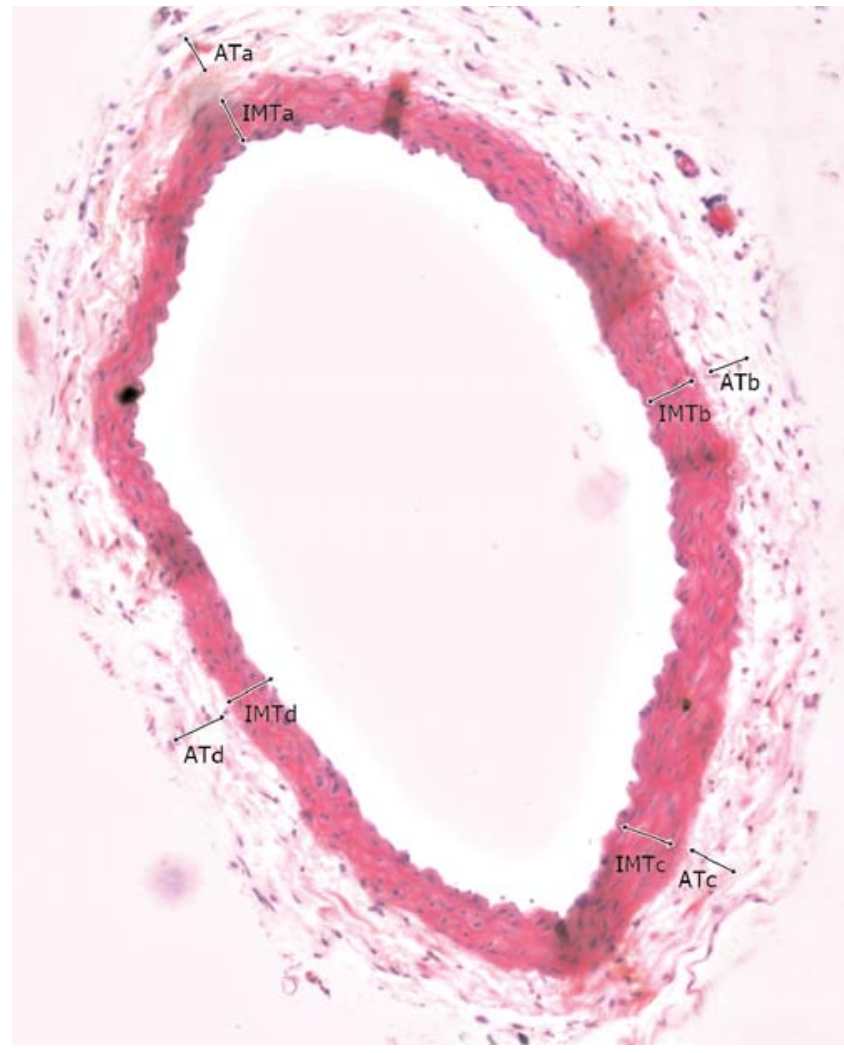

Figure 1. Estimation of common carotid wall thickness. AT: adventitia thickness; IMT: intima-media thickness. [Color figure can be viewed in the online issue, which is available at www.anatomy.org.tr]

potent antioxidant properties ${ }^{[32]}$ include scavenging reactive oxygen species and stimulating nitric oxide synthase (NOS) as described by Olalye and Rocha. ${ }^{[3]]}$ The reverse is seen in endothelial dysfunction where nitric oxide reduction and reactive oxygen species production contribute to intima media changes. ${ }^{[3]}$ The lesser collagen

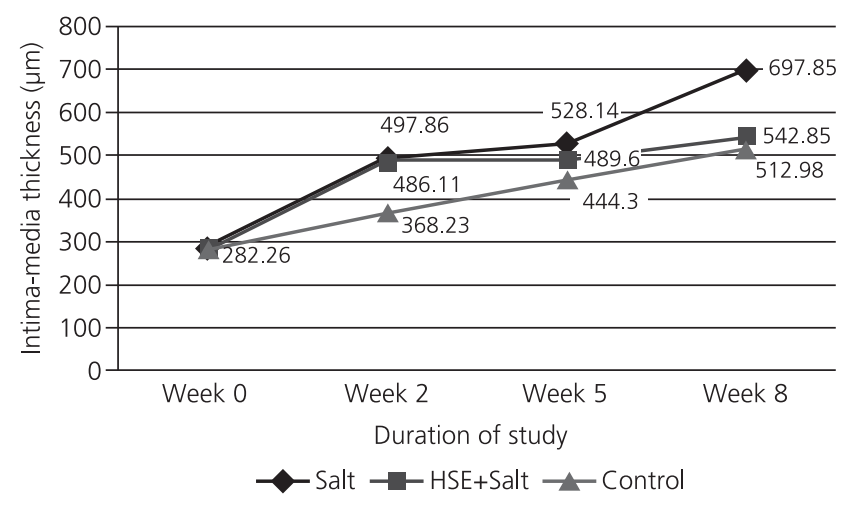

Figure 2. Line graph showing trends in intima-medial thickness in control and experimental groups. 

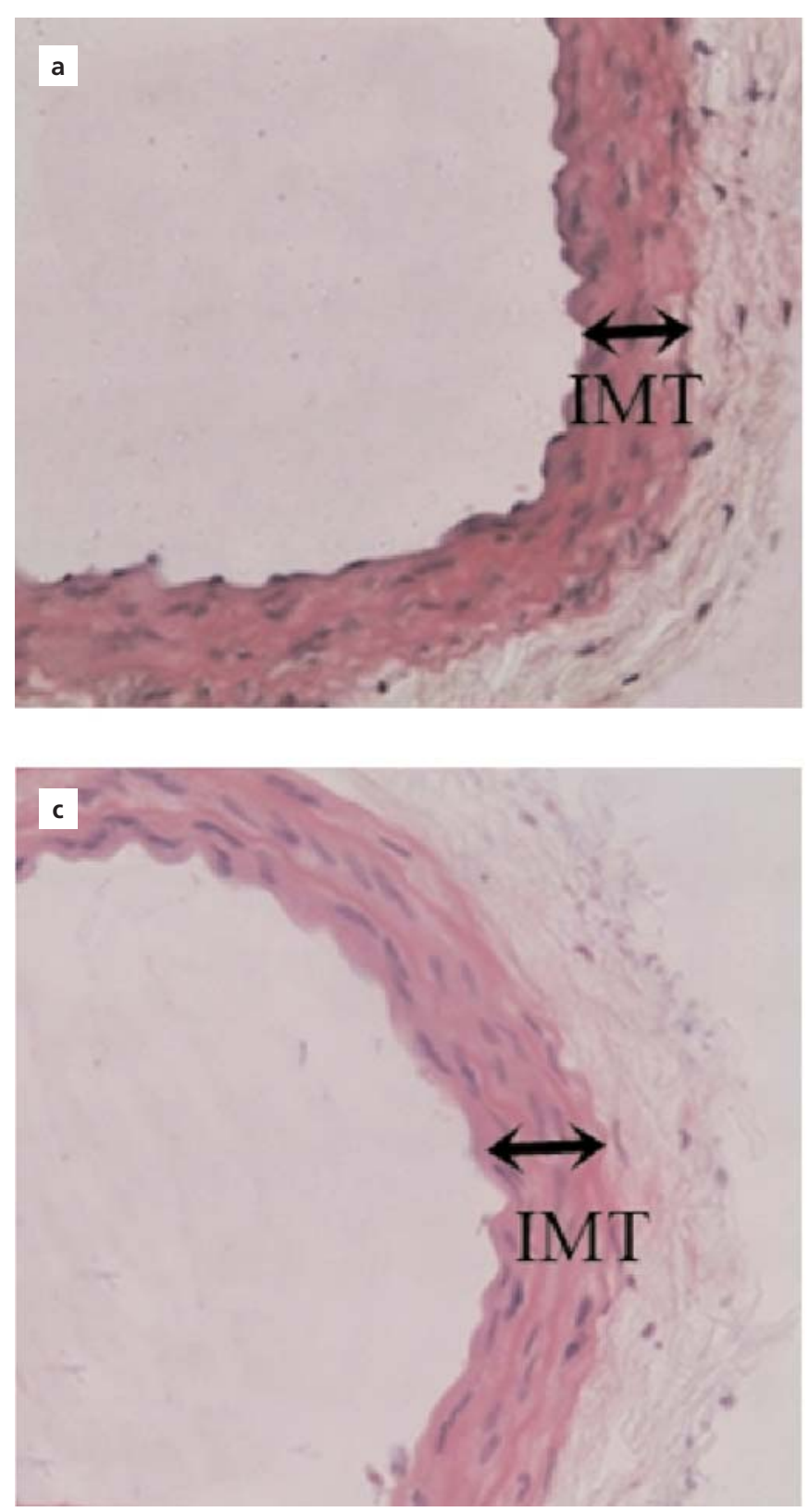

deposition and lower intima-medial thickness demonstrated in the current study therefore could be attributed to these antioxidant and other properties.

Experimental work shows that HSE has a huge potential for pharmaceutical and nutraceutical application. ${ }^{[35]}$ Hibiscus polyphenolic isolate (HPI) has been shown to suppress proliferating cell nuclear antigen (PCNA) level and MMP-2 activation. In addition, expression of connective tissue growth factor (CTGF) was prominently suppressed by HPI. ${ }^{[36]}$ Hibiscus also inhibits neointimal formation by suppressing cell proliferation, migration, apoptosis and oxidation. Accordingly,

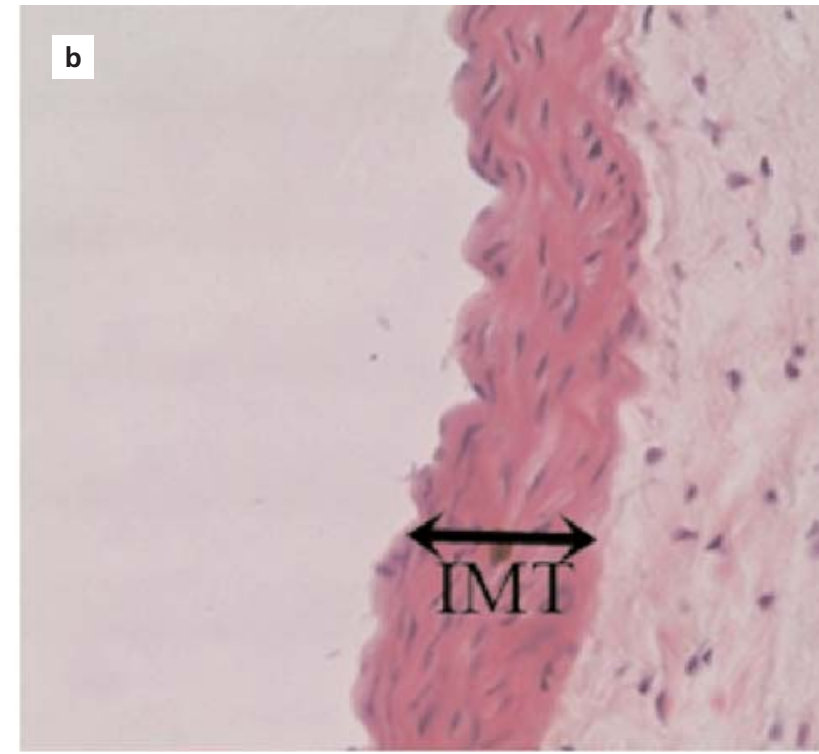

Figure 3. Photomicrographs showing the intima-media thickness of the common carotid artery in control and experimental groups at the end of the study. (a) Control group at week 8 of the study. (b) Highsalt group at week 8 of the study representing an increase in IMT when compared to Figure 3a. (c) HSE fed group at week 8. Please note that the IMT is reduced when compared to the high-salt group at week 8 in Figure 3b, but is similar to normal in Figure 3a. Haematoxylin and Eosin Stain (x400); IMT: intima-media thickness; HSE: Hibiscus sabdariffa extract. [Color figure can be viewed in the online issue, which is available at www.anatomy.org.tr]

this further demonstrates the utility of HSE in reducing CIMT and therefore reducing the risk of cardiovascular disease. Moreover, attenuation of carotid intima-media thickening as well can be a good indicator for treatment. $^{[17]}$

\section{Conclusion}

This study reveals that the Hibiscus sabdariffa extract ameliorates salt-induced increase in carotid intimamedia thickness in rats in a time-dependent manner. This implies that hibiscus products may have therapeutic value in salt-induced vascular morbidity. We recom- 
mend further studies on isolation of various components of hibiscus to elucidate the role in cardiovascular protection further.

\section{Acknowledgement}

We are grateful to staff of the Departments of Human Anatomy, Medical Biochemistry and Botany for technical assistance, and to Ms Antonina Odock for typing and editing the manuscript.

\section{References}

1. Aaron KJ, Sanders PW. Role of dietary salt and potassium intake in cardiovascular health and disease: a review of the evidence. Mayo Clinic Proc 2013;88:987-95.

2. He FJ, Li J, MacGregor GA. Effect of longer term modest salt reduction on blood pressure: Cochrane systematic review and meta - analysis of randomissed trials. BMJ 2013;346:f1325.

3. Zhao X, Yang X, Zhang X, Li Y, Zhao X, Ren L, Wang L, Gu C, Zhu Z, Han Y. Dietary salt intake and coronary atherosclerosis in patients with prehypertension. J Clin Hypertens 2014;16:575-80.

4. Xin Z, Xia Xu Y, Cheng Hui Y, Xiao Lin Z, Ya Ling H. Dietary salt intake and coronary atherosclerosis in patients with prehypertension. Heart 2015; ASSA 14-11-03.

5. Baldo MP, Rodrigues SL, Mill JG. High salt intake is a multifaceted cardiovascular disease: new support from cellular and molecular evidence. Heart Fail Rev 2015;20:461-74.

6. Chrysant SG. Effects of high salt intake on blood pressure and cardiovascular disease: the role of Cox inhibitors. Clin Cardiol 2016;39: 240-2.

7. Njoroge JN, Khoudary SRE, Fried LF, Barinas-Mitchell E, SuttonTyrrell K. High urinary sodium is associated with increased carotid intima-media thickness in normotensive overweight and obese adults. Am J Hypertens 2011;24:70-6.

8. Lorenz MW, Karbstein P, Markus HS, Sitzer M. High-sensitivity C-reactive protein is not associated with carotid intima-media progression: the carotid atherosclerosis progression study. Stroke 2007; 38:1774-9.

9. World Health Organization. Reducing salt intake in populations: report of a WHO forum and technical meeting, 5-7 October 2006, Paris, France.

10. Serban C, Sahebkar A, Ursoniu S, Andrica F, Banach M. Effect of sour tea (Hibiscus sabdariffa L.) on arterial hypertension: a systematic review and meta-analysis of randomized controlled trials. J Hypertens 2015;33:1119-27.

11. Hopkins AL, Lamm MG, Funk JL, Ritenbough C. Hibiscus sabdariffa $\mathrm{L}$ in the treatment of hypertension and hyperlipidemia: a comprehensive review of human and animal studies. Fitoterapia 2013;85:84-94.

12. Seujange Y, Leelahavanichkul A, Yisarakun W, Khawsuk W, Meepool A, Phamonleatmongkol P, Saechau W, Onlamul W, Tantiwarattanatikul P, Oonsook W, Eiam-Ong S, Eiam-Ong S. Hibiscus sabdariffa Linnaeus aqueous extracts attenuate the progression of renal injury in 5/6 nephrectomy rats. Ren Fail 2013;35:11825.

13. Guardiola S, Mach N. Therapeutic potential of Hibiscus sabdariffa: a review of the scientific evidence. [Article in Spanish] Endocrinol Nutr 2014;61:274-95.
14. Onyenekwe PC, Ajani EO, Ameh DA, Gamaniel KS. Antihypertensive effect of roselle (Hibiscus sabdariffa) calyx infusion in spontaneously hypertensive rats and a comparison of its toxicity with that in Wistar rats. Cell Biochem Funct 1999;17:199-206.

15. Sireeratawong S, Itharat A, Khonsung P, Lertprasertsuke N, Jaijoy K. Toxicity studies of the water extract from the calyces of Hibiscus sabdariffa L. in rats. Afr J Tradit Complement Altern Med 2013;10: 122-7.

16. Centurión OA. Carotid intima-media thickness as a cardiovascular risk factor and imaging pathway of atherosclerosis. Crit Pathw Cardiol 2016;15:152-60.

17. Nezu T, Hosomi N, Aoki S, Matsumoto M. Carotid intima-media thickness for atherosclerosis. J Atheroscler Thromb 2016;23:18-31.

18. Jashnani KD, Kulkarni RR Deshpande JR. Role of carotid intimamedia thickness in assessment of atherosclerosis: an autopsy study. Indian Heart J 2005;57:319-23.

19. Sofola OA, Knill A, Hainsworth, Drinkhill M. Change in endothelial function in mesenteric arteries of Sprague-Dawley rats fed a high salt diet. J Physiol 2002;543:255-60.

20. Safar ME, Thiulliez CH, Richard V, Benetos A. Pressure-independent contribution of sodium to large artery structure and function in hypertension. Cardiovasc Res 2000;46:269-76.

21. Dai XW, Wang C, Xu Y, Guan K, Su YX, Chen YM. Urinary sodium and potassium excretion and carotid atherosclerosis in Chinese men and women. Nutrients 2016;8:E612.

22. Ferreira-Sae MC, Cipolli JA, Cornélio ME, Matos-Souza JR, Fernandes MN, Schreiber R, Costa FO, Franchini KG, Rodrigues RC, Gallani MC, Nadruz W Jr. Sodium intake is associated with carotid artery structure alterations and plasma matrix metalloproteinase-9 upregulation in hypertensive adults. J Nutr 2011;141:87782.

23. Safar ME, London GM, Plante GE. Arterial stiffness and kidney function. Hypertension 2004;43:163-8.

24. Sanders PW. Vascular consequences of dietary salt intake. Am J Physiol Renal Physiol 2009;297:F237-43.

25. Ruiz-Ortega M, Rodríguez-Vita J, Sanchez-Lopez E, Carvajal G, Egido J. TGF-beta signaling in vascular fibrosis. Cardiovasc Res 2007;74:196-206.

26. Saka OS, Komolafe AO, Ogunlade O, Olayode AA, Akinjisola AA. Aqueous extract of garlic (Allium sativum) administration alleviates high salt diet-induced changes in the aorta of adult Wistar rats: a morphological and morphometric study. Anatomy 2016;10:7-15

27. de Bock M, Derraik JG, Brennan CM, Biggs JB, Morgan PE, Hodgkinson SC, Cutfield WS. Olive (Olea europaea L.) leaf polyphenols improve insulin sensitivity in middle-aged overweight men: a randomized, placebo-controlled, crossover trial. PloS One 2013;8:e57622.

28. Chen CC, Hsu JD, Wang SF, Chiang HC, Yang MY, Kao ES, Ho YC, Wang CJ. Hibiscus sabdariffa extract inhibits development of atherosclerosis in cholesterol-fed rabbits. J Agric Food Chem 2003; 51:5472-7.

29. Da-Costa-Rocha I, Bonnlaender B, Sievers H, Pischel I, Heinrich M. Hibiscus sabdariffa L. - a phytochemical and pharmacological review. Food Chem 2014;165:424-43.

30. Joven J, March I, Espinel E, Fernández-Arroyo S, RodríguezGallego E. Hibiscus sabdariffa extract lowers blood pressure and improves endothelial function. Mol Nutr Food Res 2014;58:1374-8. 
31. Beltrán-Debón R, Rodríguez-Gallego E, Fernández-Arroyo S, Senan-Campos O, Massucci FA, Hernández-Aguilera A, Joven J. The acute impact of polyphenols from Hibiscus sabdariffa in metabolic homeostasis: an approach combining metabolomics and geneexpression analyses. Food Funct 2015;6:2957-66.

32. Ekor M, Adesanoye OA, Udo IE, Adegoke OA, Raji J, Farombi EO. Hibiscus sabdariffa ethanolic extract protects against dyslipidemia and oxidative stress induced by chronic cholesterol administration in rabbits. Afr J Med Med Sci 2010;39:S161-70.

33. Olalye MT, Rocha JB. Commonly used tropical medicinal plants exhibt distinct in vitro antioxidant activities against hepatotoxins in rat liver. Exp Toxicol Pathol 2007;58:433-8.

ORCID ID:

F. O. Gwala 0000-0003-3910-2832; W. O. Sibuor 0000-0003-2886-1016;

B. O. Olabu 0000-0003-0782-8006; A. N. Pulei 0000-0003-2437-8596;

J. A. Ogeng'o 0000-0001-5918-9184

deomed.
34. Sitia S, Tomasoni L, Atzeni F, Ambrosio G, Cordiano C, Catapano A, Picano E. From endothelial dysfunction to atherosclerosis. Autoimmun Rev 2010;9:830-4.

35. Micucci M, Malaguti M, Toschi TG, Di Lecce G, Aldini R. Cardiac and vascular synergic protective effect of Olea europea L. leaves and Hibiscus sabdariffa L flower extraxts. Oxid Med Cell Longev 2015; 2015:318125.

36. Huang CN, Chan KC, Lin WT, Su SL, Wang CJ, Peng CH. Hibiscus sabdariffa inhibits vascular smooth muscle cell proliferation and migration induced by high glucose--a mechanism involves connective tissue growth factor signals. J Agric Food Chem 2009;57: 3073-9.

Correspondence to: Fidel O. Gwala, BSC

Department of Human Anatomy, School of Medicine, University of Nairobi, P.O. Box: 30197 - 00100, Nairobi, Kenya

Phone: +254 706661250

e-mail: gwalafidel@gmail.com

Conflict of interest statement: No conflicts declared.

This is an open access article distributed under the terms of the Creative Commons Attribution-NonCommercial-NoDerivs 3.0 Unported (CC BY-NC-ND3.0) Licence (http://creativecommons.org/licenses/by-nc-nd/3.0/) which permits unrestricted noncommercial use, distribution, and reproduction in any medium, provided the original work is properly cited. Please cite this article as: Gwala FO, Sibuor WO, Olabu BO, Pulei AN, Ogeng'o JA. Hibiscus ameliorates salt-induced carotid intima-media thickness in albino rats. Anatomy 2019;13(2):92-97. 